\title{
A presença da ausência na Idade Mídia
}

A morte midiatizada - como as redes sociais atualizam a experiência do fim da vida

\section{Marina ROALE ${ }^{1}$}

Não é novidade, sobretudo no campo das ciências sociais, o impacto das tecnologias digitais em várias esferas de nossas vidas, sejam elas sociais, políticas ou econômicas. À medida que vamos incorporando em nossa vida cotidiana a tarefa de conciliar nossas formas de subjetividade tanto no espaço físico como no virtual, criamse não apenas novas experiências de vida, mas também de morte. É sobre esse tema instigante que se trata o livro A morte midiatizada-Como as redes sociais atualizam a experiência do fim da vida, da jornalista e pesquisadora Renata Rezende.

A partir do conceito de hibridização dos meios de comunicação, de Muniz Sodré (2002), a autora nos convida a pensar em uma realidade marcada pela midiatização das relações socioculturais. Sob esse contexto, podemos pensar em uma forma de vida não somente mediada por dispositivos mas também transformada por eles - uma vida midiatizada. Nela todos estamos sujeitos de alguma forma, à uma representação ou performance, tendo a internet como uma espécie de mnemoteca onde nossos corpos se encontram acessíveis e "digitalizados".

No entanto, uma vez que nos "digitalizamos" para o ciberespaço, temos a chance de nos "eternizar" nesse ambiente e acrescentar tanto à vida como à morte uma nova relação com o tempo e o espaço. Isso não significa a anulação dos modos tradicionais aos quais sempre fomos condicionados a pensar tais questões, mas oferece a

\footnotetext{
${ }^{1}$ Mestranda do Programa de Pós-graduação em Mídia e Cotidiano da Universidade Federal Fluminense (UFF) - marinaroale@gmail.com
} 


\section{míDiA \\ eCris \\ DiAno}

\section{PPGMC}

coexistência de distintas formas de se existir na contemporaneidade. Levando em conta que a morte passa a ser representada, enquadrada e narrada nesses meios, a ausência se converte em presença fazendo-se necessário um estudo para entender seus desdobramentos.

O livro é estruturado em cinco partes mas, apesar de organizar-se em capítulos, permite uma leitura hipertextual e investiga o tema a partir de uma tessitura de pontos de referências que dialoga com o leitor entre diferentes perspectivas que nos estimulam a pensar o fim da vida - seja a partir de clássicos da literatura ou adotando vieses mais filosóficos que refletem as dicotomias tempo-espaço e memória-esquecimento.

O primeiro capítulo situa no mundo contemporâneo e identifica o papel das redes sociais dentro desse cenário de globalização. Vivemos na sociedade da informação marcada pela transnacionalização do sistema produtivo que se caracteriza pela aceleração dos deslocamentos. Nesse caso, a rápida e constante circulação dos produtos informacionais/culturais confere à comunicação um papel cada vez mais relevante nas estruturas de poder sociais.

A configuração de novos espaços midiáticos faz com que surjam novas formas de representações para além das tradicionais. E diferentemente da concepção adotada por alguns autores clássicos da cibercultura como Lévy (1999), que acreditava que o virtual anularia o espaço em função do tempo direcionando os corpos para um ambiente artificial, o livro aposta no pressuposto da multiplicação dos espaços e nas suas possibilidades de extensão ou atravessamento das realidades do mundo físico.

No mundo de fluxos de poder, imagens são a todo tempo ressignificadas. Considerando que as redes sociais nos "aproximam" ou "distanciam" de acordo com nossos desejos, vontades e novas interpretações simbólicas criam-se novas formas de pertencimento, identidade e vida em comum. No entanto, apesar de novas no quesito interação não perdem o caráter que define comunidade tal como a conhecemos no mundo físico e na sociologia clássica. Por isso, assim como espaços urbanos, igrejas ou 


\section{míDiA \\ eClo DiAno}

\section{PPGMC}

cemitérios, as comunidades virtuais podem se converter em um espaço de objeto de estudo para as novas narrativas sobre a morte.

Ao estudar comunidades virtuais que conectavam pessoas a partir do interesse na morte, a autora observa o paradoxal papel que ela assume: oferecer para os mortos que um projeto de permanência e continuidade de "vida" uma vez que outras pessoas se apropriam de suas narrativas dentro de espaço demarcado para isso dentro do ciberespaço.

As histórias dos mortos disponibilizadas em ambientes digitais são reconstruídas e reatualizadas, evidenciando o processo de como as identidades - ou suas múltiplas possibilidades - são reinventadas em um circuito próprio de produção articulado aos meios de comunicação e à apropriação de traços da cultura contemporânea (REZENDE, 2015, P.46).

Vale salientar, portanto que a "digitalização" do corpo que um dia esteve vivo e agora permanece "presente" apenas na rede vai além de uma simples manutenção de laços afetivos ou lembranças de um sujeito mas consiste na tentativa de alcançar a imortalidade, desejo registrado por várias civilizações em distintos momentos históricos da humanidade. Desta forma, as narrativas da rede são dotadas de significados e simbologias. Uma imagem, um texto, ou vídeo tornam-se "sufrágios contemporâneos" que os vivos possibilitam aos mortos. E mais uma vez, de forma paradoxal, observa-se que, ao passo que são os vivos que conferem uma experiência de vida aos mortos, também são os mortos capazes de transmitir uma experiência de morte aos vivos. Já que todo contato com a morte que temos é através de outros sujeitos essas comunidades não deixam de se caracterizar como um "além virtual".

Tendo esclarecido essas tensões, o segundo capítulo se encaminha para uma análise do ciberespaço convertido em espaço sagrado onde a onipresença do indivíduo possibilita um novo sentido para a morte. Esse novo sentido de transcender à carne, no entanto, nada tem de novo se revisitarmos o antigo imaginário religioso cristão da sacralização do corpo e da alma. A ideia de um Além também foi muito importante no imaginário medieval ficando evidente em importantes obras da literatura. 


\section{míDiA

Rezende cita A Divina Comédia, de Dante Alighieri, como uma das obras de referência sobre o mundo dos mortos e a utiliza para fazer uma metáfora do ciberespaço como o espaço celeste descrito na literatura em questão. A comparação se justifica a partir do momento em que nos dois casos verifica-se a criação e um universo imaginário em que o espaço é transcendido e a substância abolida. Nos dias atuais, o discurso religioso da trama dá lugar ao discurso tecnológico.

Outra analogia interessante parte da concepção de purgatório de Le Goff (1993), um local para onde os mortos iam localizado entre o Paraíso e o Inferno e só poderiam sair se houvessem preces, missas ou esmolas de amigos e parentes. E assim como no purgatório os mortos dependiam dos vivos para alcançar a vida eterna, nas comunidades virtuais dedicadas ao tema algo semelhante acontece. Além disso esse espaço une-se o tempo das duas dimensões - a terrena e a sagrada/virtual.

A junção dos espaços terrenos e celeste nos faz repensar toda a relação de tempo e espaço a partir das possibilidades do ciberespaço. Por isso, no terceiro capítulo entram para a reflexão as noções de temporalidade, com a intenção de discorrer o quanto a nossa percepção de tempo impacta na visão que temos sobre a vida e a morte. Para essa compreensão o texto se vale de questões filosóficas que com partilham de pontos aprofundados por Heidegger (2005) e Ricoeur (2007) em suas obras.

Considerando que compreendemos a nossa própria vida a partir do fim dela, o tempo constitui em uma unidade de medida, que apesar de tentar ser exata, perpassa por um conjunto de sensações subjetivas, o que faz com que o tempo humano não passe de uma forma de narrativa. "Desta forma, os indivíduos existem na medida que participam da história que os inclui - uma espécie de realidade permanente já que há uma infinita duração que precede o nascimento de cada um" (REZENDE, 2015, p.95). A configuração de tempo das comunidades virtuais, propõe uma desaceleração desse, uma vez que a noção de duração é pode ser diferente da do mundo terreno e a prolongação de um instante tenta adiar o futuro onde se encontra o fim. Trata-se da sensação de se perpetuar em um eterno presente. 


\section{míDiA \\ eCris \\ DiAno}

\section{PPGMC}

No quarto capítulo a discussão do tempo avança para a dicotomia da memória e do esquecimento, afinal só é possível lembrar porque também é possível esquecer. Retomando à obra de Dante, no ritual eucarístico se recitava os nomes dos mortos não apenas pela tentativa da lembrança, mas para recordar as histórias e os elos estabelecidos em vida. E hoje, podemos observar que o mesmo ocorre na comunidade virtual, quando o moderador convoca os vivos a postarem o perfil de algum morto conhecido. As atitudes com relação aos mortos estão intrinsecamente contidas nas memórias que se tem desses.

Além disso medo do esquecimento também é algo que foi recorrente em diversos momentos da história e que contribuiu para esse anseio da imortalidade. Pois é através de diversas mensagens, imagens e outros símbolos que a biografia de um morto se constitui no ciberespaço. Embora ela tenha se iniciado a partir dele, em vida, ela toma continuidade a partir do olhar do outro, na construção de sua memória, o que faz desta uma memória coletiva. As narrativas são reconstruídas, atualizadas ou inventadas, o que confere à morte um projeto tecnológico.

Vale retomarmos a ideia de que ainda que a sociedade da informação tenha aparentemente solucionado muitos problemas de armazenamento de memória, uma vez que nos ofereça infinitas possibilidades de registro. Enquanto na Idade Média, os suportes de escrita ou outras simbologias não tinham "sobrevivência" garantida no decorrer do tempo, no mundo contemporâneo, armazenamos tanta informação, deslocamos tantos dados que qualquer coisa, embora perpetuada em algum espaço, pode perder a atenção e, mais uma vez, cair em esquecimento.

Em contrapartida, é interessante percebermos que as comunidades virtuais sobre os mortos nos ofereceriam a possibilidade de acionar certas memórias apenas quando desejássemos, pois de certo modo, uma dose de esquecimento também seria necessária para que os vivos "seguissem em frente". O esquecimento seria então, a contingência da memória. As listas e os arquivos postados nesses espaços também possuem a função de acervo que, por vezes, assume o papel de um cemitério digital. A cruz, os retratos, as 


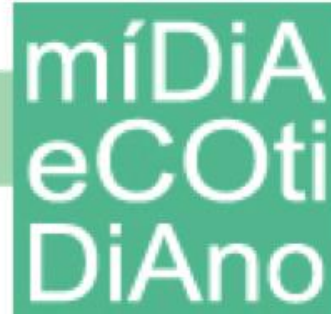

mensagens que seguem o padrão de uma lápide, todas a simbologias já associadas a um cemitério "tradicional" podem ser identificadas ali.

No quinto capítulo, o livro nos convida a pensar na perspectiva dos mortos "digitalizados" como a imaterialidade material. No ciberespaço, tanto vivos como mortos não passam de espectros, mas isso não anula suas existências, pelo contrário, os coloca no mesmo plano. As imagens e símbolos, cujos sentidos foram cultivados em um história que precede nosso nascimento, são capazes de ressignificar a experiência entre corpo e protótipo de corpo, preenchendo de materialidade o que seria à priori imaterial.

A partir de uma costura de referência que nos faz transitar da Idade Média ao momento que a autora chama de Idade Mídia, o livro se propõe a entender como "a morte é vivida, como seus efeitos são acolhidos e simbolizados, em diferentes contextos através dos tempos" (REZENDE, 215, p.214) E a partir do momento em que dispositivos tecnológicos, pensados como além de seus espaços digitais como imateriais, permitem que nossa morte seja desenhada em suportes comunicacionais, o que manifesta novos sentidos no mundo.

Por fim, o estudo da ressignificação da morte nas sociedades contemporânea nos faz pensar o quanto estamos cada vez mais sustentando na tecnologia uma tentativa de controlar nossas memórias e esquecimentos, sendo esses acionados em nossas narrativas constantemente atravessadas por diferentes temporalidades e espacialidades. Se caminhamos para um futuro que abre cada vez mais brechas e possibilidades de imaterialidade do nosso ser, todos esses esforços não passam de um velho anseio que consiste em juntar pedaços e fragmentos que possam reconstituir a matéria a qual somos ainda apegados. 